\title{
(2) OPEN ACCESS \\ Development of an international standard set of patient-centred outcome measures for overall paediatric health: a consensus process
}

\author{
Beatrix Algurén (1) 1,2,3 Jessily P Ramirez, ${ }^{3}$ Matthew Salt, ${ }^{3}$ Nick Sillett, ${ }^{3}$ \\ Stacie N Myers, ${ }^{3}$ Albie Alvarez-Cote, ${ }^{3}$ Nancy J Butcher ${ }_{1}^{4}$ Luiz F Caneo, ${ }^{5}$ \\ Jaime A Cespedes, ${ }^{6}$ John E Chaplin, ${ }^{7}$ Kee Chong Ng, ${ }^{8}$ Juan J García-García, ${ }^{9}$ \\ Jan A Hazelzet, ${ }_{10}^{10}$ Anne F Klassen, ${ }^{11}$ Aida Luiza R Turquetto, ${ }^{5}$ Emma J Mew, ${ }_{1}^{12}$ \\ Michael Morris, ${ }^{13,14}$ Martin Offringa, ${ }^{4}$ Matthew O'Meara, ${ }^{15}$ James M Papp, ${ }^{16}$ \\ Carlos Rodrigo, ${ }^{17,18}$ Timothy L Switaj, ${ }_{1}^{19}$ Catalina Valencia Mayer, ${ }^{20}$ Kathy J Jenkins ${ }^{21}$
}

- Additional material is published online only. To view please visit the journal online (http://dx.doi.org/10.1136/ archdischild-2020-320345).

For numbered affiliations see end of article.

Correspondence to Dr Beatrix Algurén, University of Gothenburg, Goteborg 405 30, Sweden; beatrix.alguren@gu.se

Received 27 July 2020

Revised 12 November 2020 Accepted 14 November 2020 Published Online First 11 December 2020
Check for updates

(c) Author(s) (or their employer(s)) 2021. Re-use permitted under CC BY-NC. No commercial re-use. See rights and permissions. Published by BMJ.

To cite: Algurén $B$,

Ramirez JP, Salt M, et al.

Arch Dis Child

2021:106:868-876.

\section{ABSTRACT}

Objective To develop an Overall Pediatric Health Standard Set (OPH-SS) of outcome measures that captures what matters to young people and their families and recognising the biopsychosocial aspects of health for all children and adolescents regardless of health condition.

Design A modified Delphi process.

Setting The International Consortium for Health Outcomes Measurement convened an international Working Group (WG) comprised of 23 international experts from 12 countries in the field of paediatrics, family medicine, psychometrics as well as patient advisors. The WG participated in 11 video-conferences, through a modified Delphi process and 9 surveys between March 2018 and January 2020 consensus was reached on a final recommended health outcome standard set. By a literature review conducted in March 2018, 1136 articles were screened for clinician and patient-reported or proxy-reported outcomes. Further, 4315 clinical trials and 12 paediatric health surveys were scanned. Between November 2019 and January 2020, the final standard set was endorsed by a patient validation $(n=270)$ and a health professional $(n=51)$ survey.

Results From a total of 63 identified outcomes, consensus was formed on a standard set of outcome measures that comprises 10 patient-reported outcomes, 5 clinician-reported measures, and 6 case-mix variables. The four developmental age-specific packages (ie, 0-5, $6-12,13-17,18-24$ years) include either five or six measures with an average time for completion of $20 \mathrm{~min}$. Conclusions The $\mathrm{OPH}-\mathrm{SS}$ is a starting point to drive value-based paediatric healthcare delivery from a global perspective for enhancing child and adolescent physical health and psychosocial well-being.

\section{INTRODUCTION}

It is a core value of any paediatric healthcare service to ensure that when a child leaves their service, they are as physically, mentally and socially healthy as possible. ${ }^{12}$ Value-based paediatric care (VBPC) requires health outcome measures to capture what

\section{What is already known on this topic?}

- Value-based paediatric care needs health outcome measures that capture what matters to young people and their families.

- Comparable data on child development irrespective of health condition are rare and not always translatable across countries.

- There is a lack of an internationally accepted standard set of outcome measures that recognise the biopsychosocial aspects of health for all children and adolescents.

\section{What this study adds?}

A consensus-based standard set of 15 health outcome measures for all young people from birth to 24 years of age, measuring 22 domains of physical, social and mental health.

- Four developmental age-specific packages made up of either five or six measures mainly patient-reported with average time of $20 \mathrm{~min}$ to complete.

- A starting point to drive value-based paediatric healthcare delivery from a global perspective.

matters most to young people and their families to enable this. ${ }^{3}$

Between March 2018 and January 2020, the International Consortium for Health Outcomes Measurement (ICHOM; www.ichom.org) convened a multidisciplinary Working Group (WG) to develop an Overall Pediatric Health Standard Set (OPH-SS). The OPH-SS comprises a minimum set of outcome measures using internationally accepted standardised measures for infants, children and adolescents regardless of health condition. Collecting and using this information consistently as a part of care delivery will position caregivers to understand determinants of child and adolescent well-being in a comprehensive way, promoting person-centred interventions and enhancing VBPC worldwide. Standardised and consistent outcomes 
assessment for all young people is likely to promote future research and quality improvement collaborations, leading to benchmarking within and across organisations, and between disease types.

\section{METHODS}

\section{The overall paediatric health Working Group}

ICHOM established a WG of 23 international experts from eight high-income countries, three upper-middle-income countries and one lower-middle-income country (online supplemental eTable 1). The WG included experts in Pediatrics, Family Medicine and Instrument Development fields across various professional backgrounds (eg, medical doctors, occupational and physical therapists). Additionally, two patient advisors (Australia and USA) who lead patient advocacy foundations were part of the WG. A Project Team (PT) guided the WG efforts and prepared the necessary materials. The project was launched in March 2018 using an iterative process of 11 WG videoconferences and subsequent rounds of electronic surveys (online supplemental eFigure $1)$.

\section{Identifying health outcomes, health outcome measures and case-mix variables}

To identify potential health outcome and corresponding outcome measures as well as case-mix variables for risk adjustment, the PT reviewed the literature and more than 4000 registered paediatric clinical trials registered in the clinical trial database (www. clinicaltrials.gov) (online supplemental eFigure 1), 12 paediatric health surveys, and the Patient-Reported Outcome Measurement Information System (PROMIS) for outcome measures used in the paediatric population. The literature review was performed in March 2018 comprising 1136 articles with 580 reviews (figure 1) (online supplemental eTable 2). First, health

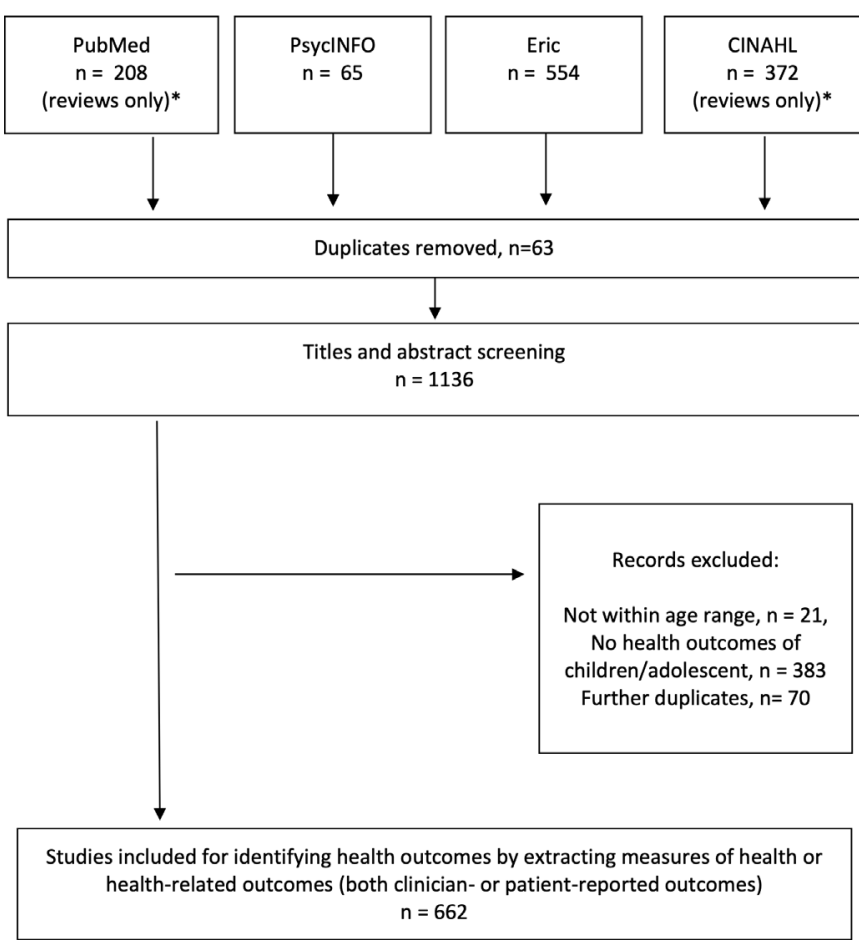

Figure 1 The flow-diagram of the literature search, conducted in March 2018 (including peer-reviewed articles from the last 10 years). * Only reviews were included due to the otherwise tremendous amount of results ( $n=20740$ and $n=12751$, respectively). outcomes were identified by categorising the extracted measures from literature according to the topic/health outcome that they were considered to measure, for example, quality of life, development, mental health and communication (online supplemental eTable 3). Overall, a total of 63 health outcomes (partly overlapping) were identified (online supplemental eFigure 2 and eTables 4-7). Second, a total of 104 measures of the agreed-upon health outcomes for inclusion were systematically evaluated to meet ICHOM's tool selection criteria, for example, available free of charge, available in English, validated and reliable (online supplemental eTables 8 and 9). Third, the contents of the eligible 26 tools were mapped to the consensus-based final 22 outcomes covered by the OPH-SS (eg, the PROMIS Pediatric Scale-Global health $7+2$ is considered to measure quality of life, mood, mobility, fitness, pain and sleep). Finally, the tools were packaged along with clinician-reported measures and an ICHOM standard measure of survival, to ensure the highest outcome coverage by age range, using a minimum number of measures. Priority was given to continuity of instruments through the four OPH-SS age ranges and highest rates of outcome coverage (online supplemental eTables 10-12).

Case-mix variables identified by the literature review were extracted to enable meaningful comparisons of child and adolescent health outcomes across treatment modalities and practices (online supplemental eTable 13).

\section{Modified Delphi and consensus process}

To reach consensus on health outcomes and outcome measures to be included in the OPH-SS, a modified Delphi process was employed (online supplemental eFigure 1). ${ }^{45}$ To capture additional patient perspectives beyond the WG level, an online survey was trialled via hospital networks with 88 parents and caregivers in Mexico. Respondents were asked to rank the 63 identified health outcomes in accordance to the importance (on a 9-point Likert Scale) for their child/children's well-being. This list was deemed to be comprehensive by $93 \%$ of parents/caregivers and the survey results were presented to $\mathrm{WG}$ prior to the first Delphi round to inform outcome selection.

Following two voting rounds, only outcomes voted as 'very important' (ie, 7-9 points) by at least $80 \%$ of WG members were included. The outcomes that did not reach consensus were discussed during WG calls (2-4) in order to balance the request to develop a minimum but comprehensive standard set. In a third vote, the inconclusive outcomes were selected by a yes/ no vote with a $70 \%$ cut-off for inclusion. This cut-off applied to the selection of outcome measure packages, age range and case-mix variables. The final OPH-SS was approved by all WG members.

\section{Consumer open review}

Between November 2019 and January 2020, an electronic survey was sent to patients and professionals. While a sample of parents and caregivers of children and adolescents in Colombia, Singapore, the USA and the UK aged at least 18 years (online supplemental eTable 14) were asked to rank the importance of the preliminary OPH-SS outcomes, paediatric and/or outcome measurement professionals were asked to indicate agreement or disagreement with: the age-ranges defined by the OPH-SS, the inclusion of each of the 22 outcomes, the selected measures per outcome and age range and case-mix-variables. In both surveys, respondents had the opportunity to leave additional free text comments. 


\section{Original research}

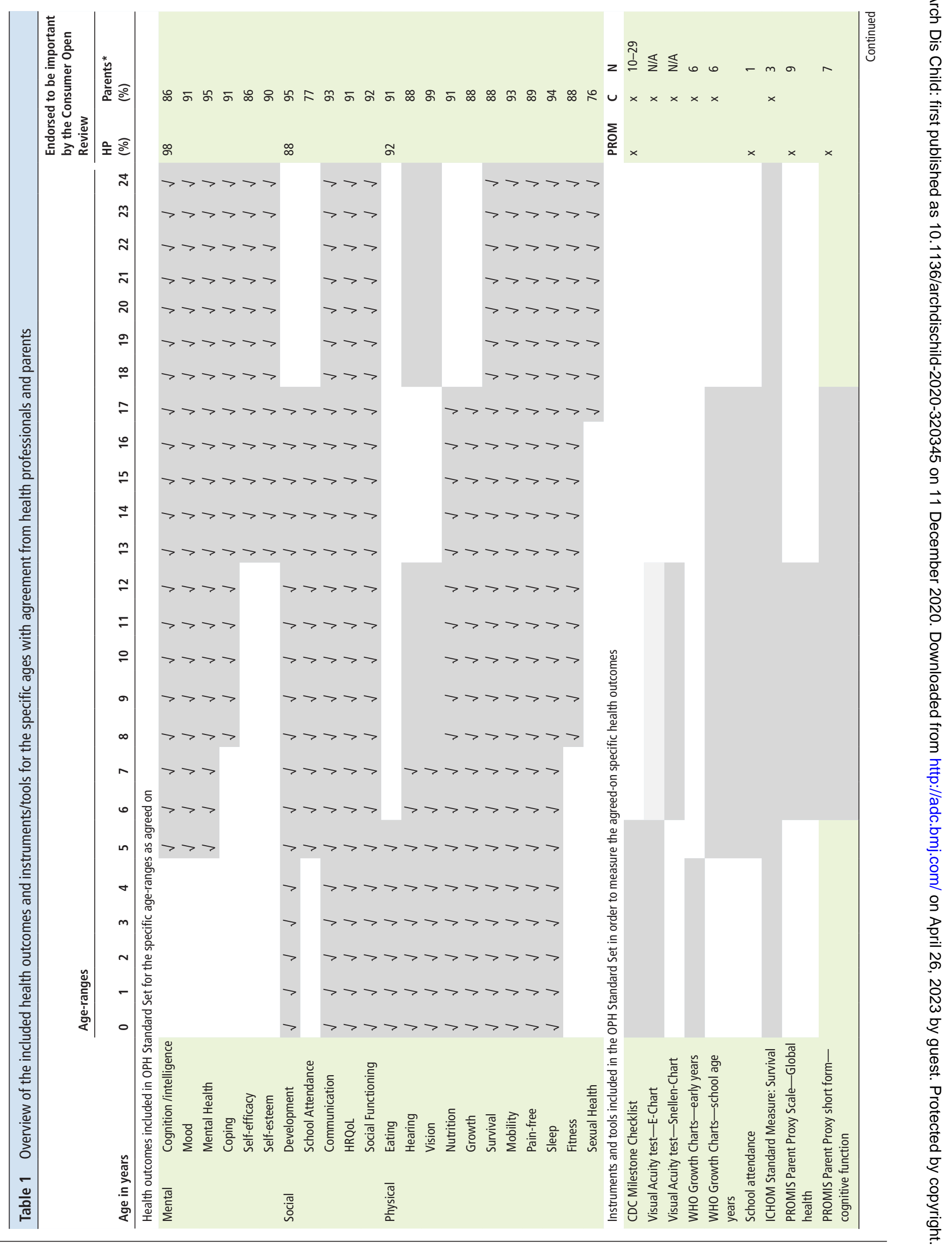




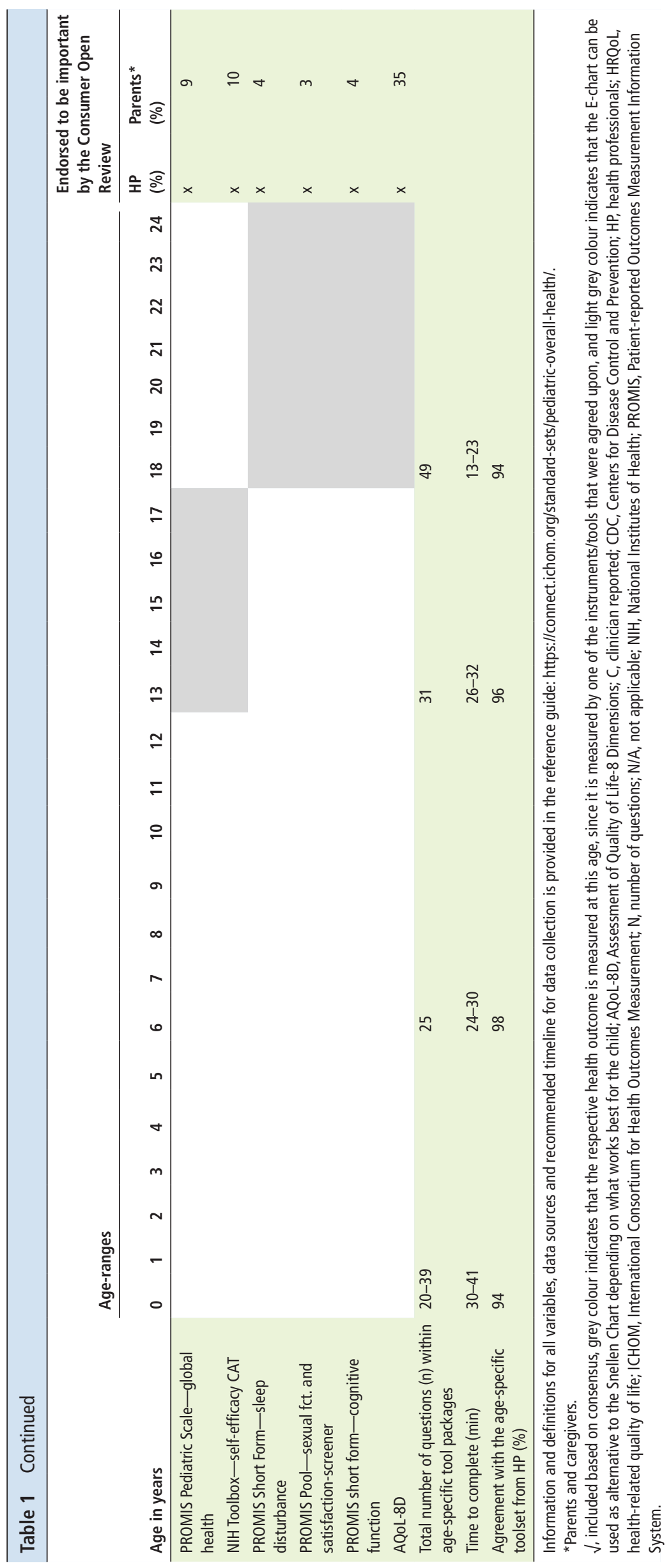




\section{Table 2 Overview of the included outcomes, measures and case-mix variables $(n=6)$, age-range specific}

\begin{tabular}{|c|c|c|c|}
\hline Age ranges & Outcome & Measures & Respondent \\
\hline \multirow[t]{5}{*}{$0-5$ years } & \multirow{5}{*}{$\begin{array}{l}\text { Survival, HRQoL, sleep, pain, mobility, } \\
\text { development, communication, hearing, social } \\
\text { functioning, vision, growth, nutrition, school } \\
\text { attendance }\end{array}$} & ICHOM Standard Measure: Survival & Clinician \\
\hline & & $\begin{array}{l}\text { CDC's Developmental Milestones Checklist (available at: https://www.cdc.gov/ } \\
\text { ncbddd/actearly/milestones/index.html) }\end{array}$ & Clinicia and patient/proxy \\
\hline & & Visual Acuity Test-E-chart & Clinician \\
\hline & & $\begin{array}{l}\text { WHO Growth Chart (Early Years) (available at: https://www.who.int/childgrowth/ } \\
\text { standards/en/) }\end{array}$ & Clinician \\
\hline & & School attendance & Patient/proxy \\
\hline \multirow{4}{*}{$\begin{array}{l}6-12 \\
\text { years }\end{array}$} & \multirow{4}{*}{$\begin{array}{l}\text { Survival, HRQoL, sleep, pain, mobility, } \\
\text { development communication, social } \\
\text { functioning, vision, growth, nutrition, school } \\
\text { attendance, cognition/intelligence, mood, } \\
\text { mental health, coping, fitness }\end{array}$} & ICHOM Standard Measure: Survival & Clinician \\
\hline & & $\begin{array}{l}\text { PROMIS Parent Proxy Scale V.1.0—Global Health 7+2 (available at: www. } \\
\text { healthmeasures.net) }\end{array}$ & Patient/proxy \\
\hline & & Visual Acuity Test-Snellen-chart (E-chart where Snellen cannot be used) & Clinician \\
\hline & & WHO Growth Chart (School-Age Years) (available at: https://www.who.int/ & Clinician \\
\hline
\end{tabular}

childgrowth/standards/en/)

School attendance

Patient/proxy

PROMIS Parent Proxy Scale V.1.0—Cognitive Function 7a (available at: www.

healthmeasures.net)

\begin{tabular}{|c|c|}
\hline $13-17$ years & $\begin{array}{l}\text { Survival, HRQoL, sleep, pain, mobility, } \\
\text { development, communication, social } \\
\text { functioning, growth, nutrition, school } \\
\text { attendance, cognition/intelligence, mood, } \\
\text { mental health, coping, fitness, self-esteem, } \\
\text { self-efficacy }\end{array}$ \\
\hline $\begin{array}{l}18-24 \\
\text { years }\end{array}$ & $\begin{array}{l}\text { Survival, HRQoL, sleep, pain, mobility, } \\
\text { communication, social functioning, vision, } \\
\text { hearing cognition/intelligence, mood, mental } \\
\text { health, coping, fitness, self-esteem, self- } \\
\text { efficacy }\end{array}$ \\
\hline
\end{tabular}

\section{ICHOM Standard Measure: Survival}

WHO Growth Chart (School-Age Years) (available at: https://www.who.int/ childgrowth/standards/en/)

School attendance

PROMIS Parent Proxy Scale V.1.0 — Cognitive Function 7a (available at: www. healthmeasures.net)

PROMIS Pediatric Scale V.1.0 - Global Health 7+2 (available at: www.

healthmeasures.net)

NIH Toolbox-Self-Efficacy CAT Ages 13-17V.2.0 (available at: www. Patient

healthmeasures.net)

ICHOM Standard Measure: Survival

PROMIS Short Form V.1.0—Sleep Disturbance 4a (available at: www.

healthmeasures.net)

PROMIS Pool V.2.0 —-Sexual Function and Satisfaction: Screeners (available at: www. Patient healthmeasures.net)

PROMIS Short Form V.2.0 — Cognitive Function 4a (available at: www. healthmeasures.net)

AQoL-8D (available at: http://www.aqol.com.au/choice-of-aqol-instrument/58.html) Patient

\section{Case-mix variable}

Age

(ICHOM Standard Measure: Age)

Sex

Diagnosis

(International Statistical Classification of Diseases and Related

Health Problems (ICD))

Parent education level

(ICHOM Standard Measure: Education (as defined by ISCED

schooling levels)/Proxy measure for socioeconomic status on other

ICHOM sets.

Primary caregiver

(Non-standard measure)

Respondent

(Non-standard measure)
Patient year and month of birth. In what year and month were you born? RESPONSE: Patient/administrative MM/YYYY

Biological sex of patient at birth. Please indicate your biological sex at birth. Patient/administrative RESPONSE: male/female/unknown

Prior and current diagnosis of disease or no presence of diagnosis. Please list any Clinician prior and current conditions.

RESPONSE: ICD-10 or SNOMED-CT/None

Please list highest level of education of either parent. RESPONSE: None/Primary/Secondary/Tertiary

Patient and/or primary caregiver

Please state the primary caregiver (check all that apply). RESPONSE: Mother or Father/Other family member/Self/Other

Who is providing this information about the patient? RESPONSE: Mother or Father/Other family member/Self/Other

These case-mix variables are recommended for all children, with an expectation that additional variables may need to be collected to allow context-specific benchmarking in some settings during implementation.

AQoL-8D, Assessment of Quality of Life-8 Dimensions; CDC, Centers for Disease Control and Prevention; ICHOM, International Consortium for Health Outcomes Measurement; PROMIS, Patientreported Outcomes Measurement Information System.

\section{Ethical considerations}

For the patient validation survey, an institutional review board (IRB) exemption review was obtained for each country (online supplemental eTable14).

\section{RESULTS}

In response to the latest debate on arbitrary age limits in paediatric care, which encourages including young adulthood, consensus was reached to include health outcome measures for newborns through 24 years of age $(75 \%) .^{6-8}$

\section{The OPH-SS: health outcomes and measures}

Through the modified Delphi process, consensus was reached to include 22 outcomes in the standard set ranging across the whole spectrum of biopsychosocial health (table 1) and are measured by 15 different tools (table 2):

- Five measures that are clinician-reported and often collected routinely in clinical practice: WHO Growth Charts-Early Years and School-Age Years versions, Visual Acuity Test-E-chart and Snellen-chart, Survival.

- Nine measures that are patient-/parent-/proxy-reported. 


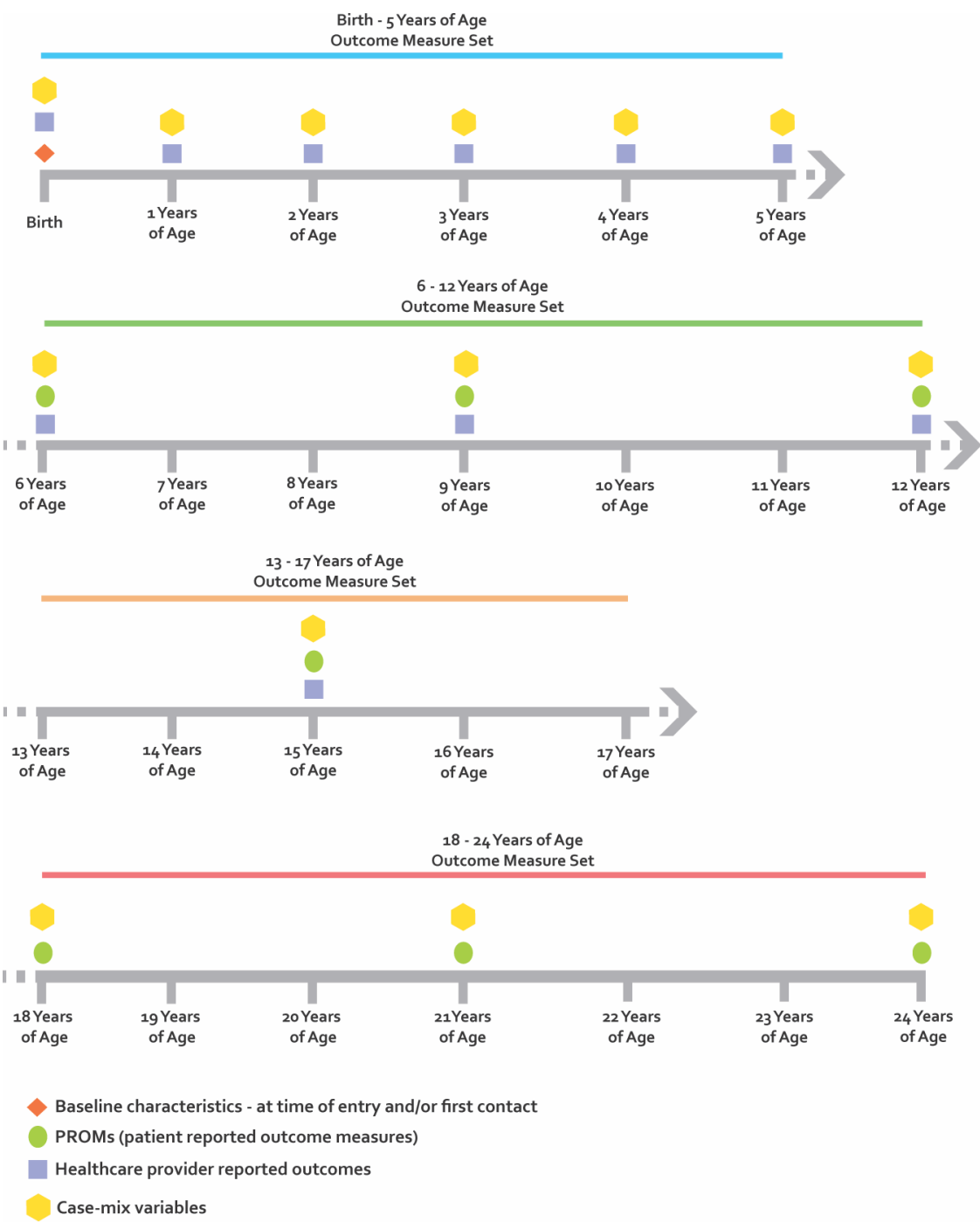

Figure 2 Proposed timeline for collecting baseline, outcome and case-mix variables for each of the four specific developmental stage subsets.

- One that is both parent/proxy and clinician-reported, the Centers for Disease Control and Prevention Developmental Milestone Checklist.

The recommended age-group specific tool packages comprise between 5 and 6 instruments/measures, with 24-49 questions, taking between 15 and $40 \mathrm{~min}$ to complete.

\section{Timepoints (in years) and frequency of measurements}

At a minimum, measurements should be taken at the point of transition between developmental stages as defined by on the National Institute of Child Health and Human Development Pediatric Terminology 9 (ages 6, 12, 18, 21 and where appropriate, age 24) (figure 2). The WG recommends optional annual measurements up to 5 years of age due to rapid development and then at ages 9 and 15 years. Since child and adolescent development varies independently of age, the use of the selected measures lends flexibility to an individual's development. ${ }^{9}$ For example, if an adolescent is sexually active before the age of 18 years, a clinician could use the PROMIS Pool v2.0- Sexual Function and Satisfaction-Screener earlier than the age of 18 years.

\section{Case-mix variables}

From a set of 30 case-mix variables identified (online supplemental eTable 13), 5 variables were included: age, sex, diagnosis, parent education level and primary caregiver and respondent (table 2). Since, several proxy-reported measures are included in the standard set, a sixth variable confirming the respondent (eg, mother/father, other family members, self, others) was included.

\section{Consumer open review}

Parents and professionals' perspectives

A total of 270 parents or caregivers of children and adolescents participated in a survey. Most respondents had one child (41\%) followed by two and three children (36\% and 17\%, respectively) with an equal sex distribution, representing the whole age-range covered by the OPH-SS (online supplemental eTable 15). At least $86 \%$ of respondents ranked 20 of the 22 outcomes as important, with slightly fewer $(76 \%)$ also deeming school attendance and sexual health as important (table 1). Almost all respondents (94\%) agreed that this list captured all the important outcomes that matter most for paediatric patients.

In a concurrent survey of paediatrics health professionals from 14 countries $(\mathrm{n}=51)$ (online supplemental eTable 16), at least $88 \%$ or more of the respondents agreed with the proposed outcomes and case-mix variables $(98 \%$ for mental and $92 \%$ for physical functioning) and over $94 \%$ agreed with the recommended measurements for each OPH-SS age-range (table 1). 
Table 3 Comments from respondents of the consumer open review survey who did not agree that the OPH-SS is complete with comments from the Working Group

\begin{tabular}{|c|c|c|c|c|}
\hline $\begin{array}{l}\text { Parents } \\
\text { (6\% did not agree) }\end{array}$ & $\begin{array}{l}\text { Professionals } \\
(2 \%-12 \% \text { did not agree })^{*}\end{array}$ & $\begin{array}{l}\text { Included in } \\
\text { OPH-SS (Yes/ } \\
\text { No) }\end{array}$ & Answers from the Working Group & $\begin{array}{l}\text { Examples of specific questions } \\
\text { contained in the included tools }\end{array}$ \\
\hline \multicolumn{5}{|l|}{ Outcomes } \\
\hline Screen time & & No & There is no standardised way to measure it yet & \\
\hline General happiness; joy & & Yes & $\begin{array}{l}\text { Included in PROMIS-General Health and } \\
\text { AQoL-8D }\end{array}$ & $\begin{array}{l}\text { How often do you feel really sad? } \\
\text { How often do you have fun with friends? } \\
\text { How often do you feel happy? } \\
\text { How often do you feel pleasure? }\end{array}$ \\
\hline Accessibility to quality healthcare & & No & $\begin{array}{l}\text { No outcome. It could be uptaken as a case-mix } \\
\text { variable, but hard to measure in a standardised } \\
\text { way worldwide. }\end{array}$ & \\
\hline $\begin{array}{l}\text { Social interaction with peers and } \\
\text { parents; social well-being; social } \\
\text { environment in family and with } \\
\text { friends }\end{array}$ & $\begin{array}{l}\text { Social interactions with family, peers } \\
\text { and adults should be defined by its } \\
\text { own outcome separately from general } \\
\text { functioning and development. }\end{array}$ & Yes & $\begin{array}{l}\text { Included in PROMIS-General Health and } \\
\text { AQoL-8D. } \\
\text { We tried to reduce the amount of tools and } \\
\text { questions to answer in order to increase } \\
\text { the uptake and feasibility of the OPH-SS. } \\
\text { Therefore, it is not measured by a specific social } \\
\text { interaction instrument. }\end{array}$ & $\begin{array}{l}\text { How often do you feel socially excluded } \\
\text { or left out? } \\
\text { How often do you have fun with friends? } \\
\text { How often do your parents listen to your } \\
\text { ideas? } \\
\text { Does your health affect your relationship } \\
\text { with your family? } \\
\text { How satisfying are your close relationships } \\
\text { (family and friends)? } \\
\text { How much do you enjoy your close } \\
\text { relationships (family and friends)? How } \\
\text { often do you feel socially isolated? }\end{array}$ \\
\hline Treatment in school & & No & $\begin{array}{l}\text { Not qualified to be included in a minimum set } \\
\text { of health outcomes }\end{array}$ & \\
\hline Bullying & & Yes (?) & $\begin{array}{l}\text { It might be detected by questions in PROMIS- } \\
\text { General Health and AQoL-8D }\end{array}$ & $\begin{array}{l}\text { How often do you feel socially excluded } \\
\text { or left out? } \\
\text { How often do you have fun with friends? } \\
\text { How often do you feel socially isolated? }\end{array}$ \\
\hline \multirow[t]{3}{*}{ Fine motor skills } & & Yes & $\begin{array}{l}\text { Measured by CDC's Developmental Milestones } \\
\text { Checklist. }\end{array}$ & $\begin{array}{l}\text { Makes or copies straight lines and circles; } \\
\text { Pours, cuts with supervision, and mashes } \\
\text { own food; Uses a fork and spoon and } \\
\text { sometimes a table knife }\end{array}$ \\
\hline & $\begin{array}{l}\text { Lifestyle factors, including addictions, } \\
\text { should be included in the older age } \\
\text { ranges. }\end{array}$ & No & $\begin{array}{l}\text { Not qualified to be included in a minimum set } \\
\text { of health outcomes }\end{array}$ & \\
\hline & $\begin{array}{l}\text { Hearing should be assessed for all age } \\
\text { ranges. }\end{array}$ & Yes/No & $\begin{array}{l}\text { It is not measured by any tool only for one age } \\
\text { range between } 13 \text { and } 17 \text { years. }\end{array}$ & \\
\hline \multicolumn{5}{|l|}{ Case-mix } \\
\hline $\begin{array}{l}\text { Health problems/medical condition/ } \\
\text { disease specifics }\end{array}$ & & Yes & Measured by Case-mix variable 'Diagnosis' & ICD-10 or Snomed-CT \\
\hline \multirow[t]{3}{*}{ Genetics } & & No & $\begin{array}{l}\text { Not feasible to measure worldwide, ethical } \\
\text { aspects have to be considered }\end{array}$ & \\
\hline & $\begin{array}{l}\text { Home environment in terms of parents } \\
\text { and access to food, healthcare and } \\
\text { sanitation. }\end{array}$ & No & $\begin{array}{l}\text { Not qualified to be included in a minimum set } \\
\text { of health outcomes }\end{array}$ & \\
\hline & $\begin{array}{l}\text { Presence of complications during } \\
\text { pregnancy as well as prematurity of } \\
\text { the infant }\end{array}$ & No & $\begin{array}{l}\text { Not qualified to be included in a minimum set } \\
\text { of health outcomes }\end{array}$ & \\
\hline
\end{tabular}

*For more information about agreement of completeness from health professionals, see table 1.

AQoL-8D, Assessment of Quality of Life-8 Dimensions; OPH-SS, Overall Pediatric Health Standard Set; PROMIS, Patient-Reported Outcome Measurement Information System.

Comments from both parents and professionals who did not agree are presented in table 3 with comments from the WG.

\section{Reference guide}

In order to facilitate the adoption and implementation of the OPH-SS, a reference guide was developed by ICHOM (https:// connect.ichom.org/standard-sets/pediatric-overall-health/). It provides information and definitions for all variables, data sources and a recommended timeline for data collection.

\section{DISCUSSION}

The OPH-SS comprises 10 PROMs and 5 clinician-reported validated and reliable measures, using between 5 and 6 measurements for each of the four developmental age-stages, with an average completion time of $20 \mathrm{~min}$. Ultimately, healthcare should be 'patient-centred' and put 'each patient in control of his or her own care'. ${ }^{10}$ Therefore, the OPH-SS is recommended for routine use in clinical practice to assess health outcomes and facilitate and empower young people and parents to make shared decisions about their care, with their caregivers. $^{11} 12$

To allow meaningful comparisons across different settings and countries, six case-mix variables addressing demographic, clinical and parental (or primary caregiver) risk factors are included. This is a multidisciplinary standard set of paediatric outcome measurements developed to measure the overall biopsychosocial health and the well-being of anyone up to 24 years of age. ${ }^{8}$ All measures are free of licensing fees and most are available in multiple languages to reduce barriers to uptake of the standard set internationally. 
For the OPH-SS to drive VBPC, widespread implementation strategies to incorporate measures in routine clinical practice and existing workflows throughout various paediatric care settings will be critical. Meaningful, relevant and actionable comparative benchmarking practices need to be developed and refined. Implementation and adoption should allow healthcare comparison across different settings and countries to facilitating local and global improvements in paediatric care delivery and promoting international cross-cultural paediatric research.

\section{Limitations}

In order to minimise the burden of documentation and time to completion, the recommended measures cover several outcomes and comprise a minimum set of questions. The WG aimed to strike a balance between measuring each outcome using a specific instrument and risking double documentation or including instruments that measure broader concepts covering a variety of outcomes. Sum scores can be calculated for the included broader concepts (eg, quality of life, self-efficacy). While the global implementation of the OPH-SS allows further psychometric testing of the included measures for various populations, more comprehensive measures may be needed to increase validity and sensitivity for specific important outcomes. The feasibility of implementing the OPH-SS may vary between different countries and healthcare systems. As a result of varying technological access, representation from lowincome countries could not be included during the consensus process diminished as the WG process progressed. The ICHOM process is iterative and a Steering Committee, comprised of former WG members, will serve as a stewarding body to ensure that the $\mathrm{OPH}-\mathrm{SS}$ remains up to date with the most current evidence and is revised in line with feedback received from implementation experiences across communities.

\section{CONCLUSION}

Based on an extensive literature review, assessment of clinical trials and registries, international patient input and paediatric expert consensus, a minimal set of 15 health outcome measures was developed. To our knowledge, this is the first set of paediatric outcome measurements not specific to any health condition but applicable to the overall biopsychosocial health and well-being of any infant, child or adolescent throughout all developmental stages from birth to 24 years of age. With the implementation of this set in daily clinical practice worldwide, care delivery teams should be increasingly accountable to promote well-being of individuals, with a subsequent understanding of the quality of care being delivered. Comprehensive evaluation of outcomes and discussion of the results with patients and parents will facilitate shared decision-making between families and their healthcare providers. Health literacy will also likely improve, ensuring that families will be sufficiently knowledgeable about the healthcare they receive, ultimately resulting in more equitable care delivery, globally. The next steps will be to implement the $\mathrm{OPH}-\mathrm{SS}$ in the current clinical workflow, harmonising data collection with electronic health records and registries and developing strategies to provide the data back to clinical teams and patients, creating a meaningful process to drive value-based healthcare.

\footnotetext{
Author affiliations

${ }^{1}$ Department of Food and Nutrition, and Sport Science, Faculty of Education, University of Gothenburg, Göteborg, Sweden

${ }^{2}$ Jönköping Academy for Improvement of Health and Welfare, School of Health Sciences, Jönköping University, Jönköping, Sweden

${ }^{3}$ International Consortium for Health Outcomes Measurements (ICHOM), Boston, Massachusetts, USA

${ }^{4}$ Child Health Evaluative Sciences, Hospital for Sick Children, University of Toronto, Toronto, Ontario, Canada
}

${ }^{5}$ Heart Institute, University of Sao Paulo Medical School, Sao Paulo, Brazil

${ }^{6}$ Fundacion Cardioinfantil- Instituto de Cardiologia, Universidad del Rosario, Bogota, Colombia

${ }^{7}$ Department of Pediatrics, Institute of Clinical Sciences, University of Gothenburg, Göteborg, Sweden

${ }^{8}$ KK Women \& Children's Hospital, Singapore

${ }^{9}$ Hospital Sant Joan de Déu, Barcelona, Spain

${ }^{10}$ Department of Public Health, Erasmus Medical Centre, Rotterdam, The Netherlands

${ }^{11}$ Department of Pediatrics, McMaster University, Hamilton, Ontario, Canada

${ }^{12}$ Child Health Evaluative Sciences, The Hospital for Sick Children Research Institute, Toronto, Ontario, Canada

${ }^{13}$ Samuel Morris Foundation, Sydney, New South Wales, Australia

${ }^{14}$ Sydney Children's Hospital Networks, Sydney, New South Wales, Australia

${ }^{15}$ NSW Health, Sydney, New South Wales, Australia

${ }^{16}$ Mindful Metrics, LLC, Cincinnati, Ohio, USA

${ }^{17}$ Pediatrics, Germans Trias i Pujol University Hospital, Badalona, Catalunya, Spain

${ }^{18}$ Universitat Autònoma de Barcelona Facultat de Medicina, Bellaterra, Catalunya, Spain

${ }^{19}$ U.S. Army, Boston, Massachusetts, USA

${ }^{20}$ Fundación CINDA - Universidad El Bosque, Bogotá, Colombia

${ }^{21}$ Boston Children's Hospital, Boston, Massachusetts, USA

Twitter Nancy J Butcher @NancyJButcher, Jan A Hazelzet @janhazelzet, Anne F Klassen@anneklassen and Carlos Rodrigo@crodrigogl

Acknowledgements We would like to thank all WG members, patient representatives and professionals, for their time and effort developing this $\mathrm{OPH}-\mathrm{SS}$ without financial remuneration.

Contributors BA, as a member of the Project Team performed the literature search and analysis, prepared materials for the consensus process, drafted the manuscript and finalised it in collaboration with all authors. JR, MS, NS and SM as members of the Project Team performed analysis, prepared materials for the consensus process, revised the manuscript and approved the final version prior to submission. KJ, as Working Group Chair and member of the Project Team led the group by promoting the vision for the project and guiding the consensus building process, revised the manuscript and approved the final version prior to submission. AA-C, NB, LC, JaC, JoC, NKC, JJG-G, JH, AK, ALRT, EM, MM, MO, MO'M, JP, CRGdL, TS, CV, as members of the working group participated in discussions and consensus process, revised the manuscript and approved the final version prior to submission.

Funding The development of this standard set was made possible by the generous contributions from the following sponsors: NSW Agency for Clinical Innovation, Boston Children's Hospital, Erasmus Medical Center (Sophia Children's Hospital), KK Women and Children's Hospital, Cincinnati Children's Hospital Medical Center, Health Service Executive, Meyer Children's Hospital, Hospital Sant Joan de Déu, The Hospital for Sick Children and Fundación Cardioinfantil—Instituto de Cardiología.

Disclaimer The views expressed herein are those of the author (TLS) and do not reflect the official policy or positon of Brooke Army Medical Center, the U.S. Army Medical Department, the U.S. Army Office of the Surgeon General, the Department of the Army, the Department of the Air Force, or the Department of Defense, or the U.S. Government

Competing interests JEC is a Swedish national representative for the PROMIS Health Organisation and DISABKIDS Quality-of-Life measurement system.

Patient consent for publication Not required.

Provenance and peer review Not commissioned; externally peer reviewed.

Data availability statement All data relevant to the study are included in the article or uploaded as supplementary information. Not applicable.

Supplemental material This content has been supplied by the author(s). It has not been vetted by BMJ Publishing Group Limited (BMJ) and may not have been peer-reviewed. Any opinions or recommendations discussed are solely those of the author(s) and are not endorsed by BMJ. BMJ disclaims all liability and responsibility arising from any reliance placed on the content. Where the content includes any translated material, BMJ does not warrant the accuracy and reliability of the translations (including but not limited to local regulations, clinical guidelines, terminology, drug names and drug dosages), and is not responsible for any error and/or omissions arising from translation and adaptation or otherwise.

Open access This is an open access article distributed in accordance with the Creative Commons Attribution Non Commercial (CC BY-NC 4.0) license, which permits others to distribute, remix, adapt, build upon this work non-commercially, and license their derivative works on different terms, provided the original work is properly cited, appropriate credit is given, any changes made indicated, and the use is non-commercial. See: http://creativecommons.org/licenses/by-nc/4.0/.

ORCID iD

Beatrix Algurén http://orcid.org/0000-0001-9993-8741 


\section{Original research}

\section{REFERENCES}

1 Flanagan P, Tigue PM, Perrin J. The value proposition for pediatric care. JAMA Pediatr 2019;173:1125-6.

2 Chua K-P, Conti RM, Freed GL. Appropriately framing child health care spending: a prerequisite for value improvement. JAMA 2018;319:1087-8.

3 Bae J-M. Value-Based medicine: concepts and application. Epidemiol Health 2015;37:e2015014.

4 Hsu C, Sandford B. The Delphi technique: making sense of consensus. Practical Assessment, Research \& Evaluation 2007;12:1-8.

5 Sinha IP, Smyth RL, Williamson PR. Using the Delphi technique to determine which outcomes to measure in clinical trials: recommendations for the future based on a systematic review of existing studies. PLoS Med 2011;8:e1000393.
6 Hardin AP, Hackell JM, Committee on practice and ambulatory medicine. Age limit of pediatrics. Pediatrics 2017;140:e20172151.

7 Sawyer SM, Azzopardi PS, Wickremarathne D, et al. The age of adolescence. Lancet Child Adolesc Health 2018;2:223-8.

8 Sawyer SM, McNeil R, Francis KL, et al. The age of paediatrics. Lancet Child Adolesc Health 2019;3:822-30.

9 Williams K, Thomson D, Seto I, et al. Standard 6: age groups for pediatric trials. Pediatrics 2012:129 Suppl 3:S153-60.

10 Institute of Medicine. Crossing the quality chasm: a new health system for the twentyfirst century. Washington: National Academy Press, 2001.

11 Ciani O, Federici CB. Value lies in the eye of the patients: the why, what, and how of patient-reported outcomes measures. Clin Ther 2020;42:25-33.

12 Meyer GS, Nelson EC, Pryor DB, et al. More quality measures versus measuring what matters: a call for balance and parsimony. BMJ Qual Saf 2012;21:964-8. 